\title{
ESTRUTURA INFORMATIZADA PARA PROCESSOS NO CENTRO DE MATERIAL E ESTERILIZAÇÃO
}

\author{
Computerized structure for procedures at the central sterile services department
}

\author{
Estructura informatizada para procedimientos en el centro de material y esterilización \\ Alisson Francisco Vargas Rodrigues ${ }^{1 *} \oplus$, Daniela Silva dos Santos Schneider ${ }^{2} \oplus$, Denise Tolfo Silveira ${ }^{3} \oplus$, \\ Ivana Trevisan ${ }^{4} \oplus$, Maximiliano Dutra de Camargo ${ }^{5} \odot$, Elisabeth Gomes da Rocha Thomé 6 ๑
}

RESUMO: Objetivo: Descrever as etapas de desenvolvimento e avaliação da estrutura informatizada para processamento de bandejas cirúrgicas na área de preparo do centro de material e esterilização. Método: Trata-se de um projeto de desenvolvimento de produção tecnológica embasada na teoria de "ciclo de vida do sistema”. Resultados: A estrutura foi criada utilizando formulários e planilhas do Google Apps. Os formulários foram desenvolvidos com base na coleta de informações das referências gravadas nos instrumentais, consulta ao nome correto nos catálogos dos fabricantes e registros fotográficos de detalhes das peças. Foi realizada a avaliação pelos colaboradores, e foram feitas as alterações sugeridas pelos mesmos. Os formulários permitiram identificar o nome do instrumental e a referência do fabricante e acessar as fotos dos materiais, o que passou a gerar planilhas que permitiram a rastreabilidade e o gerenciamento dos materiais cirúrgicos. Conclusão: A informatização do preparo das bandejas de cirurgia minimamente invasiva contribuiu para o preparo de maneira fácil, intuitiva e de forma rastreável. A tecnologia pode otimizar o tempo de assistência do enfermeiro do centro de material e esterilização com as questões relacionadas ao planejamento das ações gerenciais e à rastreabilidade dos processos.

Palavras-chave: Centro cirúrgico hospitalar. Sistemas de informação. Instrumentos cirúrgicos. Esterilização

ABSTRACT: Objective: To describe the stages of development and evaluation of the computerized structure for the processing of surgical trays processing at the preparation room of the central sterile services department (CSSD). Method: This is a technological production development project based on the "system life cycle" theory. Results: The structure was created using Google Apps forms and spreadsheets. The forms were developed based on the collection of information from references recorded in the surgical instruments, and checking of correct names in manufacturers' catalogs and photographic records of details of the parts. The evaluation was performed by the employees, and changes suggested by them were applied. The forms allowed to identify the name each surgical instrument and the manufacturer's reference, and to access the photos of materials, which was input to spreadsheets that allowed the keeping track of and managing surgical instruments. Conclusion: The computerization of the process of preparation of minimally invasive surgery trays made it easier, more intuitive and traceable. Technology can optimize the nursing care time at the CSSD in what concerns the planning of actions and the keeping track of procedures.

Keywords: Surgery department, hospital. Information systems. Surgical instruments. Sterilization.

RESUMEN: Objetivo: Describir las etapas de desarrollo y evaluación de la estructura informatizada para el procesamiento de bandejas quirúrgicas en el área de preparación del centro de material y esterilización. Método: Se trata de un proyecto de desarrollo de producción tecnológica basada en la teoría de "ciclo de vida del sistema". Resultados: La estructura se creó utilizando formularios y hojas de cálculo de Google Apps. Los formularios fueron

'Enfermeiro. Enfermeiro do Hospital Tacchini - Bento Gonçalves (RS), Brasil.

${ }^{2}$ Enfermeira; mestre em Toxicologia Aplicada. Enfermeira da Central de Material Esterilizado do Hospital de Clínicas de Porto Alegre - Porto Alegre (RS), Brasil.

${ }^{3}$ Doutora em Ciências. Professora Associada da Escola de Enfermagem do Departamento de Enfermagem Médico-Cirúrgica da Universidade Federal do Rio Grande do Sul (UFRGS) - Porto Alegre (RS), Brasil.

${ }^{4}$ Enfermeira; mestre em Enfermagem. Enfermeira do Hospital de Clínicas de Porto Alegre - Porto Alegre (RS), Brasil.

${ }^{5}$ Enfermeiro pela UFRGS - Porto Alegre (RS), Brasil.

${ }^{6}$ Doutora em Enfermagem. Professora Adjunta do Departamento de Enfermagem Médico-Cirúrgica da Escola de Enfermagem da UFRGS - Porto Alegre (RS), Brasil.

*Autor correspondente: alisson.fvr@gmail.com

Recebido: 26/08/2018 - Aprovado: 01/05/2019

DOI: $10.5327 / Z 1414-4425201900020009$ 
desarrollados en base a la recolección de informaciones de las referencias grabadas en los instrumentos, consulta al nombre correcto en los catálogos de los fabricantes y registros fotográficos de detalles de las piezas. Se realizó la evaluación por los colaboradores, y se efectuaron las alteraciones sugeridas por los colaboradores. Los formularios permitieron identificar el nombre del instrumental y la referencia del fabricante y acceder a las fotos de los materiales, lo que pasó a generar hojas que permitieron la trazabilidad y la gestión de los materiales quirúrgicos. Conclusión: La informatización de la preparación de las bandejas de cirugía mínimamente invasiva contribuyó a la preparación de manera fácil, intuitiva y de forma rastreable. La tecnología puede optimizar el tiempo de asistencia del enfermero del centro de material y esterilización con las cuestiones relacionadas con la planificación de las acciones gerenciales y la trazabilidad de los procesos.

Palabras clave: Servicio de cirugía en hospital. Sistemas de información. Instrumentos quirúrgicos. Esterilización.

\section{INTRODUÇÃO}

Ano após ano, as instituições hospitalares tendem a ser auditadas, tanto financeiramente quanto sobre a qualidade do serviço prestado, sendo este um desafio a ser superado. Em busca de melhorias, os gestores hospitalares, em geral, sabem da importância da tecnologia da informação (TI) para a instituição, porém não a priorizam em suas gestões, sendo colocada em segundo plano, atrás das atividades assistenciais, consultas, medicações, reformas das unidades, entre outras atividades ${ }^{1}$.

O uso de sistemas informatizados permite o acesso imediato a informações e processos, contribuindo no planejamento da assistência, gerenciamento de custos e tomada de decisões, de modo a auxiliar na eficiência do sistema institucional ${ }^{1}$.

O centro de material e esterilização (CME), no contexto da assistência ao paciente, se enquadra como uma unidade funcional destinada ao processamento de produtos para a saúde. Esse processamento engloba um conjunto de ações, como a pré-limpeza, seguindo para etapas relacionadas à recepção, secagem, avaliação da integridade e da funcionalidade, preparo, esterilização, armazenamento e distribuição para as unidades consumidoras ${ }^{2}$. O enfermeiro desse setor tem a tarefa de gerenciar, organizar e planejar processos, desenvolvendo atividades de gestão de processos e de materiais, tendo como uma das responsabilidades garantir a segurança da esterilização dos materiais que serão utilizados no desenvolvimento da assistência ao paciente ${ }^{3}$.

Visto isto, o enfermeiro é um dos profissionais mais capacitados para o gerenciamento de materiais hospitalares. Ele, por formação, é conduzido para atividades de gerenciamento, lança mão de normativas de regulação sanitárias e legislação para avaliar a melhor escolha de materiais que atendam às necessidades de pacientes e profissionais, com qualidade e segurança no cuidado ${ }^{4}$.

A inovação tecnológica repercute cada dia mais na atividade do enfermeiro, provocando a necessidade de compreensão desses profissionais para o fato de que serão cada vez mais presentes, na sua prática, ferramentas informatizadas que podem contribuir fortemente para o aprimoramento do cuidado. Na sua atividade diária é imprescindível, por exemplo, que o enfermeiro do CME consiga saber, em tempo real, a localização dos instrumentais cirúrgicos de forma dinâmica e rápida, utilizando algum tipo de sistema informatizado para sua rastreabilidade.

Segundo a Associação Brasileira de Normas Técnicas (ABNT), na NBR ISO 9000, o processo de rastreabilidade é definido pela capacidade de rastrear o histórico, a aplicação, o uso e a localização de uma mercadoria individual 5 . Partindo desse princípio, no CME, a informação mais importante é relativa à origem e ao destino das bandejas cirúrgicas. Todavia, para que o processo de rastreabilidade desse setor seja transparente e rotineiro, sua aplicação não deve ser vista como uma obrigação, mas como uma ferramenta auxiliar para a tomada de decisão e o gerenciamento da qualidade ${ }^{6}$.

Ao observar o fluxo de trabalho do CME, identifica-se que ele envolve conceitos de logística, que incluem a sessão do processo de gestão da cadeia de suprimentos, que trata do planejamento, da implementação e do controle eficiente e eficaz do fluxo e da armazenagem de bens, serviços e informações relacionados, do seu ponto de origem até o seu ponto de consumo, de modo a satisfazer as necessidades dos clientes ${ }^{7}$.

No CME, o fluxo de processos é o ponto-chave. A logística deve ser clara, rápida e eficiente, com o objetivo de atender às demandas dos consumidores finais, os usuários do serviço hospitalar.

Para tanto, foi desenvolvida uma estrutura informatizada que viabilizasse o processo de rastreabilidade para o $\mathrm{CME}$ na área de preparo de bandejas cirúrgicas e que atendesse às necessidades de banco de dados gerado a partir desse processo, como suporte a outros indicadores de gestão e qualidade do serviço.

Nessa perspectiva, este artigo tem como premissa descrever as etapas de desenvolvimento e avaliação da estrutura informatizada para processamento de bandejas cirúrgicas na área de 
preparo do CME, além de contribuir com informações e proposições que favoreçam a reflexão na construção do conhecimento em enfermagem no campo de sistemas de informação.

\section{OBJETIVO}

Descrever as etapas de desenvolvimento e avaliação da estrutura informatizada para processamento de bandejas cirúrgicas na área de preparo do CME.

\section{MÉTODO}

Trata-se de um projeto de desenvolvimento de produção tecnológica baseada na teoria de "ciclo de vida do sistema", composta por sete fases: reconhecimento do problema, estudo de viabilidade, análise (a respeito das atividades do sistema atual, necessidades físicas, como hardwares, softwares; custo e benefício por atividade e requisitos da base de dados), projeto detalhado (desenvolvidos fluxogramas de programas, leiautes dos arquivos, descrição dos dados e outros), implementação, testes e manutenção ${ }^{8}$.

A tecnologia escolhida para a construção da estrutura informatizada foi o Google Apps. O formulário eletrônico é preenchido pela equipe de enfermagem via dispositivo móvel ou em computadores. Para cada inclusão de um formulário é gerada uma linha na planilha do Google. Essa estrutura informatizada está em um site hospedado na nuvem, que também foi desenvolvido com a ferramenta do Google com controles de perfil de acesso às informações, por meio do uso de Grupos do Google e regras de compartilhamento.

O estudo foi realizado no CME do Hospital de Clínicas de Porto Alegre (HCPA), uma instituição pública vinculada academicamente à Universidade Federal do Rio Grande do Sul (UFRGS), que faz parte de uma rede de hospitais universitários do Ministério da Educação (MEC). Sua excelência em gestão, infraestrutura, atendimento e qualificação profissional é certificada desde 2013 pela acreditação da Join Comission Internatinal (JCI $)^{9}$.

O CME atende a todos os processos de desinfecção e esterilização da instituição e está vinculado ao serviço de enfermagem em centro cirúrgico (SECC), que é composto de quatro unidades: bloco cirúrgico, centro cirúrgico ambulatorial, sala de recuperação e $\mathrm{CME}^{10}$.

Este estudo foi realizado seguindo os preceitos da Resolução $n^{\circ} 466 / 2012$, que regulamenta as normas éticas para pesquisas envolvendo seres humanos ${ }^{11}$. O projeto foi aprovado pela Comissão de Pesquisa da Escola de Enfermagem (COMPESQ/ ENF) da UFRGS e pelo Comitê de Ética em Pesquisa do HCPA (CEP/HCPA), sob o $\mathrm{n}^{\circ}$ 64023317.8.0000.5327, via Plataforma Brasil.

O presente estudo apresenta relevância social, ao servir como estrutura e ferramenta para gerenciamento dos processos do CME na ótica da rastreabilidade e do gerenciamento da qualidade do serviço de saúde.

\section{RESULTADOS}

O resultado da pesquisa foi a aplicação das etapas de desenvolvimento, baseada na teoria do "ciclo de vida do sistema".

\section{Reconhecimento do problema}

O reconhecimento do problema deu-se por meio das atividades das enfermeiras do CME do HCPA, que observaram a necessidade de informatizar o sistema que, até então, era feito manualmente; coletar informações de produção de determinada etapa do processo de rastreabilidade; e, por fim, atenuar a probabilidade de erros de montagem de kits cirúrgicos.

\section{Estudo de viabilidade}

Foram realizadas reuniões com as chefias do SECC da instituição e profissionais de enfermagem do CME para discutir a viabilidade da aplicabilidade da estrutura informatizada no CME. O projeto priorizou, então, iniciar pela área de preparo de material no CME, trabalhando com apenas uma especialidade cirúrgica, a videocirurgia.

\section{Análise}

Nessa etapa foram consultados quatro técnicos de enfermagem, especialistas em montagens de bandejas cirúrgicas de videocirurgia, sobre como poderia ser mais fácil a visualização dos formulários e o acesso a eles.

A estrutura informatizada para o preparo de bandejas cirúrgicas utilizou recursos do Google Drive, tais como: Formulários Google, Planilhas Google e Drive de Equipe. Os formulários foram usados na parte operacional da área de preparo do CME e as planilhas, usadas como banco de dados para gerenciamento dos materiais cirúrgicos. Foi acordado que o acesso se daria por meio do uso do QR code. 


\section{Projeto}

A ideia da estrutura informatizada foi discutida e amadurecida com um enfermeiro, com experiência em construção de sites utilizando o Google Sites e Google Formulários, escolhido pelo primeiro pesquisador. Esse profissional idealizou e estruturou um primeiro formulário, usado para pré-teste com os funcionários do CME.

O formulário pré-teste foi avaliado pelos futuros usuários do sistema quanto à estrutura e o mesmo foi modificado, facilitando o trabalho a ser realizado. Após o término da criação de todos os formulários e suas planilhas, foram feitas diversas reuniões com especialistas da área de TI do hospital, gestores do CME, enfermeiras e técnicos de enfermagem, revisando sobre o acesso ao conteúdo de forma dinâmica e menos estressante.

\section{Implementação}

Nessa etapa, a estrutura informatizada foi implementada, seguindo-se os passos descritos a seguir:

Todo o material de uma especialidade cirúrgica foi fotografado e, posteriormente, as fotos foram editadas e salvas no Google Drive;

As fichas, que antes eram usadas para a montagem de bandejas, foram retiradas e informatizadas, usando os formulários Google, que contêm links para consulta das fotos dos materiais usados para a montagem da bandeja (Figura 1);

Para cada bandeja foi criado um QR code (Figura 2) e este foi compartilhado com a equipe de enfermagem. Esse código fez o link para os formulários Google;

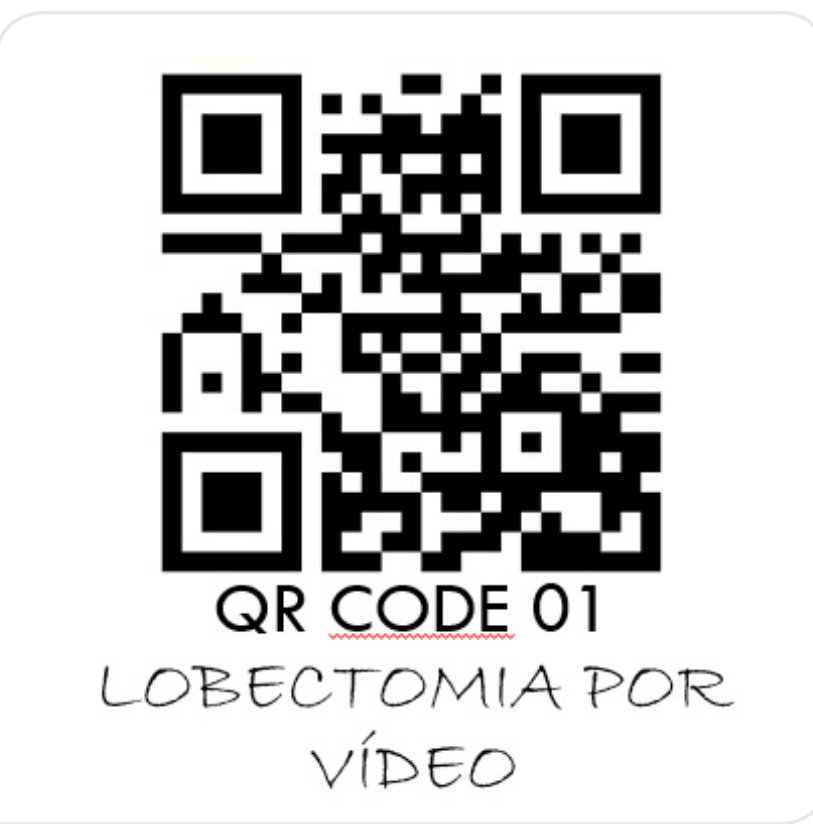

Figura 2. Modelo de QR code utilizado.

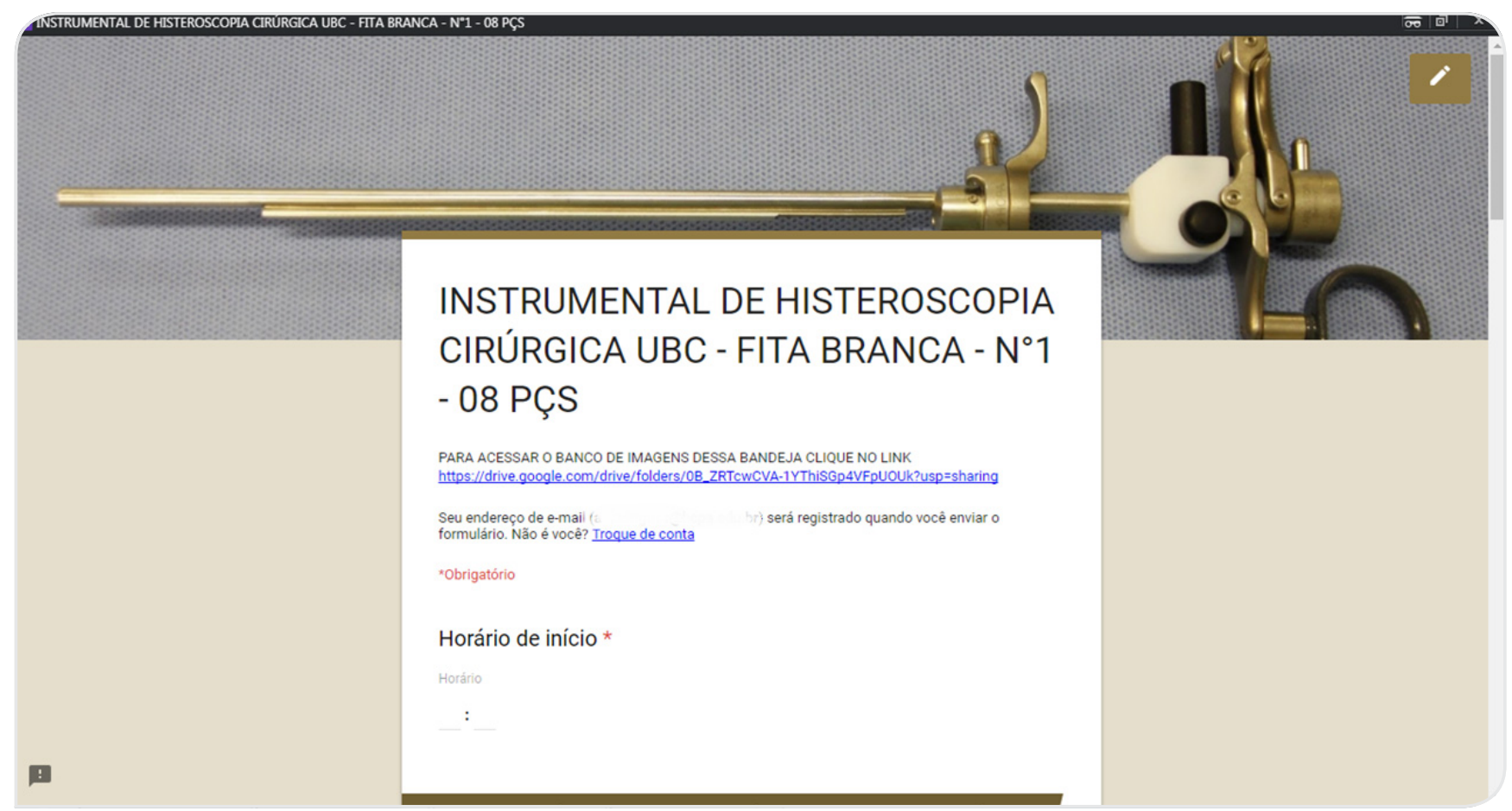

Figura 1. Formulário Google criado a partir das fichas de montagem de bandejas. 
Cada bancada da área de preparo possui um computador e uma webcam que realiza a leitura dos QR codes. Atendendo aos critérios de compatibilidade das webcams e ao sistema operacional dos computadores do setor, o software gratuito Quickmark foi a estrutura encontrada;

Utilizando o Quickmark, a webcam é ativada para realizar a leitura do QR code, abrindo o formulário correspondente automaticamente. Depois, é necessário fazer login com o $e$-mail e senha usados na instituição.

A partir desse momento, o funcionário realiza a montagem da bandeja com os materiais descritos no formulário, sendo todas as respostas obrigatórias (Figura 3);
No fim do formulário, é opcional que o extrato das respostas seja enviado para o e-mail do colaborador.

Ao final da montagem da bandeja, as respostas aparecem em uma nova linha gerada em uma planilha Google correspondente (Figura 4), oferecendo informações, em tempo real, do que está sendo produzido no turno de trabalho para os gestores, nesse caso, as enfermeiras da unidade;

Pelas regras de compartilhamento do Google Drive e formulários Google, foi definido quem poderia responder aos formulários e visualizar as fotos dos materiais cirúrgicos. Nesse caso, qualquer funcionário que detenha o $e$-mail institucional poderá acessar os formulários dentro das dependências do CME.

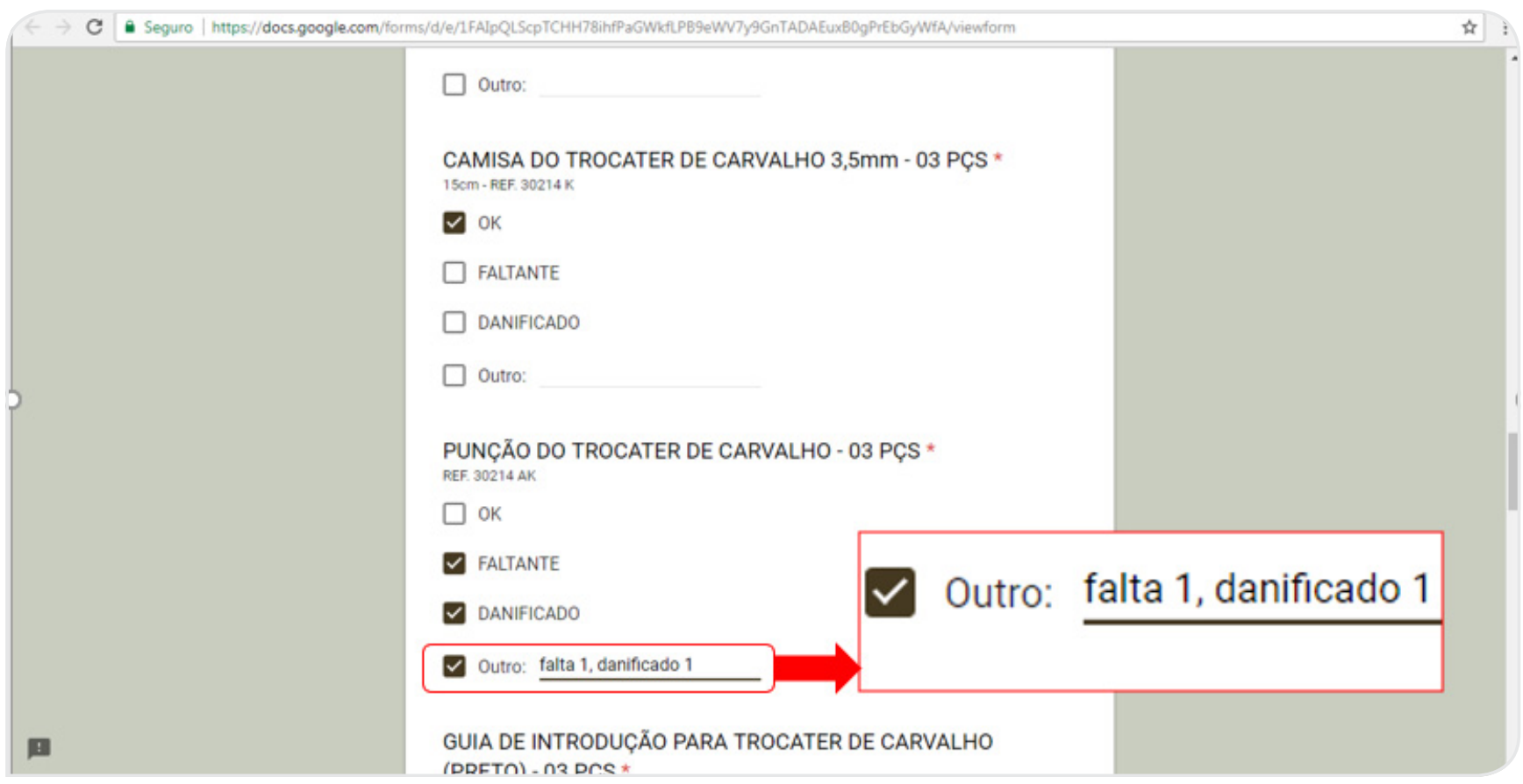

Figura 3. Exemplo de respostas que podem ser feitas dentro do formulário Google.

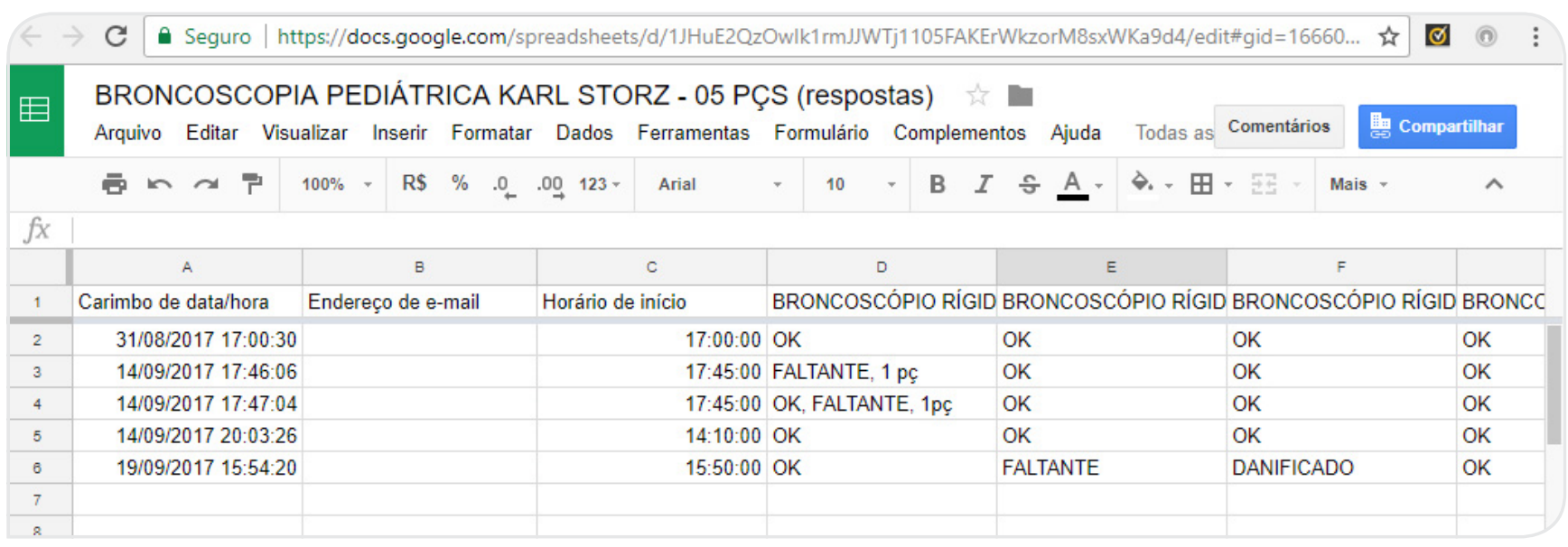

Figura 4. Relatório gerado pelos formulários Google a partir das respostas dos usuários. 


\section{Testes}

A proposta para este momento foi a implantação de um piloto no setor de preparo do CME, para aferir na prática operacional em uma única especialidade cirúrgica, avaliada pelos especialistas por um instrumento fundamentado de acordo com o padrão ISO/IEC 25.010.

\section{Manutenção}

Quando chegamos a essa fase, o sistema já havia passado pelos testes de aceitação e foi considerado pronto para a entrega. No caso de necessidade de qualquer alteração no sistema a partir da entrega, essa necessidade foi denominada de manutenção ${ }^{8}$.

$\mathrm{Na}$ fase atual, a estrutura informatizada para rastreabilidade de bandejas cirúrgicas não necessitou de manutenção, mas está prevista de acordo com as etapas do ciclo de vida dos sistemas.

\section{DISCUSSÃO}

A estrutura informatizada para viabilização da rastreabilidade de materiais cirúrgicos foi construída dentro de uma lógica inovadora e de baixo custo para a instituição. Especialmente, se comparada ao disponível no mercado em termos de software para rastreabilidade e com alto custo de aquisição e suporte, essa estrutura torna-se mais atrativa para ser multiplicada em outras instituições de saúde.

Todavia, muitas das ideias inovadoras não são divulgadas no meio científico, limitando-se a informações locais em jornais ou televisão, não sendo aprofundadas, como deveriam, para mostrar o real efeito na assistência. Por vezes, essas mesmas notícias descredibilizam o sistema que tenta ser implantado, quando causam mínima lentidão no processo, sem conhecer a real importância do sistema na organização e gestão ${ }^{1}$.

A fase de análise foi uma das mais desgastantes, por causa da pesquisa de compatibilidade do software disponível na instituição, do hardware no orçamento do projeto e dos recursos humanos necessários para viabilizar a sua construção. Segundo a ISO/IEC 25.000, que avalia a qualidade dos softwares, a compatibilidade é a capacidade de troca de informações entre softwares, de maneira que haja bom desempenho nas funções requeridas, enquanto eles compartilham recursos de hardware e software, sem que nenhum interrompa o funcionamento um do outro ou de outros produtos ${ }^{12}$.
Como a estrutura informatizada foi criada no Google Drive, ele permite que qualquer funcionário do hospital possa fazer login e acessar os formulários, pois o login do e-mail corporativo (Gmail) é o mesmo utilizado para acessar os formulários, sendo fácil a conectividade dos Google Apps.

Todo o projeto foi criado utilizando o Google Drive, mais especificamente os Formulários Google e Planilhas Google. Os formulários foram usados para a parte operacional na área de preparo do CME e as planilhas, que são geradas por meio desses formulários, são usadas como banco de dados para subsidiar o melhor gerenciamento dos materiais cirúrgicos.

A empresa norte americana, criadora dos aplicativos em questão, visa tornar as informações mundialmente acessíveis e organizadas com produtos baseados na internet. Suas ferramentas têm ampla recursividade e são de fácil aplicabilidade, permitindo o trabalho coletivo entre usuários, de modo que sejam possíveis a edição e a colaboração simultânea em um único documento de forma dinâmica, possibilitando novas experiências ${ }^{13}$.

Esses apps também foram escolhidos devido à sua similaridade com programas do Office, como Word, Excel e PowerPoint, o que causou menos estranheza aos usuários, pelo fato desses programas serem, atualmente, muito popularizados, com exceção dos Formulários Google ${ }^{14}$.

Com a criação de todos os formulários e de suas planilhas, foram feitas diversas reuniões com especialistas da área de TI do hospital, gestores, enfermeiras e técnicos de enfermagem do CME, sobre o acesso a esse conteúdo de forma dinâmica, e foi acordado que esse acesso se daria por meio do QR code.

Para atender à facilidade de acesso aos formulários, o QR code foi identificado como a melhor solução tecnológica, por se tratar de um código de barras de resposta rápida bidimensional que, quando comparado com outros códigos, incluindo clássicos unidimensionais, pode armazenar mais informações e acessar uma página da web ${ }^{15}$.

Outro ponto positivo para adesão ao $\mathrm{QR}$ code é que ele pode ser gerado por inúmeros softwares e aplicativos disponíveis na internet, basicamente transformando um texto bruto, nesse caso um link da web, em uma matriz de código bidimensional ${ }^{16}$.

É fato que estamos em uma época de constante renovação e inovação tecnológica, portanto se faz necessária a busca de soluções sem custos de aquisição e suporte e que funcionem em diversos sistemas operacionais e configurações de hardware (sistema multiplataforma) ${ }^{17}$.

Todo o sistema foi criado com o objetivo de possibilitar que o profissional enfermeiro, líder de uma equipe e que 
gerencia o setor, possa exercer suas atividades em tempo real, otimizando seu tempo de assistência, para que ele consiga absorver suas demandas diárias e organizar melhor os fluxos e as rotinas da unidade, dando subsídio para controlar o que está sendo produzido diariamente ${ }^{18}$.

\section{CONSIDERAÇ̃̃ES FINAIS}

A estrutura informatizada aplicada conseguiu atender aos objetivos contemplados neste estudo, viabilizando o início da informatização do processo de rastreabilidade no CME da instituição sede do estudo, o HCPA.

Todo o escopo do sistema foi pensado juntamente com a equipe de enfermagem, com o objetivo de agilizar o processo de montagem de bandejas cirúrgicas, a confiabilidade dos dados coletados, a dinamicidade do trabalho da equipe de enfermagem e a monitorização da produção diária ou turno a turno.

O processo de implementação dessa tecnologia no setor não foi tão simples como o esperado, por conta da grande dificuldade de interação do software e do hardware disponíveis. Com isso, o setor de TI da instituição foi essencial para que tudo funcionasse de forma estável.

O estudo favoreceu a reflexão de que a enfermagem precisa de atualização no campo dos sistemas de informação. Sendo assim, a tecnologia otimiza o tempo de assistência do enfermeiro com as questões burocráticas e proporciona o planejamento das ações em cima de dados atualizados constantemente.

\section{REFERÊNCIAS}

1. Santos TO, Pereira LP, Silveira DT. Implantação de sistemas informatizados na saúde: uma revisão sistemática. Rev Eletron Comunicação Informação Inovação Saúde. 2017;11(3):1-11. http:// dx.doi.org/10.29397/reciis.v11i3.1064

2. Brasil. Ministério da Saúde. Agência Nacional de Vigilância Sanitária. Resolução da Diretoria Colegiada (ANVISA) RDC no 15 de 15 de março de 2012. Dispõe sobre requisitos de boas práticas para o processamento de produtos para saúde e dá outras providências. Diário Oficial da União da República Federativa do Brasil. 2012.

3. Associação Brasileira de Enfermeiros de Centro Cirúrgico, Recuperação Anestésica e Centro de Material e Esterilização. Diretrizes de práticas em enfermagem cirúrgica e processamento de produtos para saúde. 7a ed. São Paulo: SOBECC; 2017.

4. Bogo PC, Bernardino E, Castilho V, CruzED. The nurse in the management of materials in teaching hospitals. Rev Esc Enferm USP. 2015;49(4):6329. http://dx.doi.org/10.1590/S0080-623420150000400014

5. Associação Brasileira de Normas Técnicas. NBR ISO 9000: Sistemas de gestão da qualidade: fundamentos e vocabulário. $3^{\mathrm{a}} \mathrm{ed}$. Rio de Janeiro: ABNT; 2015

6. Campos MRR. Gestão de estoques com rastreabilidade de materiais: estudo de caso de impactos no inventário de uma indústria eletrônica. Rev Ciên Gerenc. 2008;12(15):177-94. http://dx.doi. org/10.17921/1415-6571.2008v12n15p177-194

7. Council of Supply Chain Management Professionals. Supply chain management terms and glossary [Internet]. Lombard: Council of Supply Chain Management Professionals [acessado em 10 set. 2017]. Disponivel em: https://cscmp.org/imis0/CSCMP/Educate/SCM_Definitions_and_ Glossery_of_Terms/CSCMP/Educate/SCM_Definitions_and_Glossary of_Terms.aspx?hkey=60879588-f65f-4ab5-8c4b-6878815ef921
8. Meilir PJ. Projeto estruturado de sistemas. São Paulo: McGrawHill; 1988.

9. Hospital de Clinicas de Porto Alegre. Institucional/Apresentação: Características [Internet]. Porto Alegre: Hospital de Clinicas de Porto Alegre [acessado em 27 set. 2018]. Disponível em: https:// www.hcpa.edu.br/institucional/institucional-apresentacao/ institucional-apresentacao-caracteristicas

10. Hospital de Clinicas de Porto Alegre. Serviços de Enfermagem: Enfermagem em Centro Cirúrgico [Internet]. Porto Alegre: Hospital de Clinicas de Porto Alegre [acessado em 27 set. 2018]. Disponível em: https://www.hcpa.edu.br/assistencia-servicos-de-enfermagemenfermagem-em-centro-cirurgico

11. Brasil. Conselho Nacional de Saúde. Resolução n 466, 12 de dezembro de 2012. Diretrizes e normas regulamentadoras de pesquisa envolvendo seres humanos. [Internet]. 2012 [acessado em 07 jul. 2017. Disponível em: http://bvsms.saude.gov.br/bvs/saudelegis/ cns/2013/res0466_12_12_2012.html

12. Organização Internacional de Normalização. ISO/IEC 25000. Software engineering: System and Software Quality Requirements and Evaluation (SQuaRE). Genebra: ISO; 2014.

13. Sampaio A, Oliveira L, Gomes E. Formação docente em aplicativos Google Drive: desafios colocados à prática docente. Rev Estudios Investigación en Psicología y Educación. 2017;(13):168-71. http:// dx.doi.org/10.17979/reipe.2017.0.13.2659

14. Ramos R, Ramos S, Asega F. Google Drive: potencialidades para o design de Material Educacional Digital (MED) para ensino de línguas. The Especialist. 2017;38(1):1-17. http://dx.doi. org/10.23925/2318-7115.2017v38i1a6 
15. Liu C, Shi L, Xu X, LiH, Xing H, Liang D, et al. O código de barras do DNA é de duas dimensões: o servidor web do código QR do DNA. PloSone [Internet]. 2012 [acessado em 15 ago. 2017];7(5):e35146. Disponível em: http://www.ncbi.nlm.nih.gov/pmc/articles/PMC3344831/pdf/ pone.0035146.pdf

16. Barrera JF, Mira-Agudelo A, Torroba R. Experimental QR code optical encryption: noise-free data recovering. Opt Lett. 2014;39(10);30747. http://dx.doi.org/10.1364/OL.39.003074
17. Santos SR. Informática em enfermagem: desenvolvimento de software livre com aplicação assistencial e gerencial. Rev Esc Enferm USP. 2010;44(2):295-301. http://dx.doi.org/10.1590/ S0080-62342010000200008

18. Camargo MD, Martinato LHM, Silveira DT. Higienização hospitalar: etapas de desenvolvimento em ambiente de intranet. J Health Inform [Internet]. 2015 [acessado em 10 dez. 2017];7(4):121-6. Disponível em: http://www.jhi-sbis.saude.ws/ojs-jhi/index.php/jhi-sbis/article/ view/362/244

\section{4}

